\title{
Escritores Públicos y Prensa en la Nueva Granada, 1848-1853*
}

\author{
José Camilo Becerra Mora
}

Afiliado institucionalmente a la Universidad Pedagógica y Tecnológica de Colombia - UPTC (Colombia). Correo electrónico: josecamilo.becerra@uptc.edu.co. El autor es magíster en Historia por la Universidad Pedagógica y Tecnológica de Colombia - UPTC (Colombia). Entre sus temas de interés se encuentran Historia de Colombia, Historia política, Historia intelectual, Historia de la democracia.

Recibido: 29 de mayo de 2020

Aprobado: 14 de julio de 2020

Modificado: 23 de julio de 2020

Artículo de investigación científica

DOI: https://doi.org/10.15648/hc.38.2021.2820

Este artículo forma parte del proyecto "Los intelectuales en Nueva Granada 1848-1854. Fase I" financiado por Universidad Pedagógica y Tecnológica de Colombia (Colombia).

Esta publicación está bajo una licencia Creative Commons Reconocimiento-NoComercial 4.0 (cc) BY-NC 


\section{Escritores Públicos y Prensa en la Nueva Granada, 1848-1853}

\section{Resumen}

El propósito del presente artículo es caracterizar a los publicistas neogranadinos entre 1848 y 1853. Para materializar este objetivo, la primera parte analiza el rol de la prensa en la configuración de un tipo inédito de escritor público. La segunda sección expone las facetas que desarrollaron aquellos letrados. Estudiar a los escritores públicos constituye un avance importante en el análisis de los partidos políticos como elementos fundamentales en la configuración de lo que Pierre Rosanvallon denominó como lo político, pues como se intentará demostrar, quienes se encargaron de configurar los partidos políticos, se preocuparon por dotarlos con elementos intelectuales complejos ${ }^{1}$.

Palabras clave: escritores públicos, publicistas, partidos políticos, prensa, Nueva Granada.

\section{Public writers and press in the New Granada, 1848-1853}

\section{Abstract}

The purpose of this paper is to describe the public authors from New Granada from 1848 to 1853 . In order to bring this goal to fruition, in the first part is analyzed the press role in the composition of an unprecedented type of a public author. In the second part are exposed, the different sides developed by those authors in political life in New Granada. Studying public writers constitutes an important advance in the analysis of political parties as fundamental elements in the configuration of what Pierre Rosanvallon has called the political, because as will be tried to demonstrate, those who were in charge of configuring political parties, they worried about equipping them with complex intellectual elements.

Key words: public authors, political Journalist, political parties, press, New Granada.

\section{Escritores públicos e prensa na Nueva Granada, 1848-1853}

\section{Resumo}

O objetivo deste artigo é caracterizar os publicitários ou escritores públicos de

1 Pierre Rosanvallon, Por una historia conceptual de lo político (Buenos Aires: Fondo de Cultura Económica, 2003), 19-20. 
República de Nova Granada entre os anos de 1848 e 1853. Para atingir este objetivo, na primeira parte propõe-se analisar o papel da imprensa na configuração de um tipo inédito de escritor público. A segunda seção expõe-se as diferentes facetas que aqueles letrados desenvolveram na política da Nova Granada. Em resumo, o artigo procura estudar, a intervenção de escritores públicos em diferentes cenários da vida política e intelectual neogranadina em meados do século XIX. O estudo de escritores públicos constitui um avanço importante na análise dos partidos políticos como elementos fundamentais na configuração do que Pierre Rosanvallon chamou de político, porque, como será tentado demonstrar, os responsáveis pela configuração dos partidos políticos, eles se preocupavam em equipá-los com elementos intelectuais complexos.

Palavras-chave: escritores públicos, anunciantes, partidos políticos, imprensa, Nova Granada

\section{Écrivains publics et presse en Nouvelle-Grenade, 1848-1853}

\section{Resumé}

Le but de cet article est de caractériser les publicistes néo-grenadiens entre 1848 et 1853. Pour y parvenir, la première partie analyse le rôle de la presse dans la configuration d'un type inédit d'écrivain public. La deuxième section expose les facettes que ces écrivains ont développées. L'étude des écrivains publics constitue une avancée importante dans l'analyse des partis politiques en tant qu'éléments fondamentaux de la configuration de ce que Pierre Rosanvallon a appelé le politique, car comme on tentera de le démontrer, ceux qui ont façonné les partis politiques, se sont préoccupés de les doter d'éléments intellectuels complexes.

Mots clés: écrivains publics, publicistes, partis politiques, presse, la Nouvelle Grenade.

\section{INTRODUCCIÓN}

Es innegable que el periodo comprendido entre 1848 y 1853 fue importante en el desarrollo político e intelectual de la Colombia decimonónica. Este tiempo estuvo caracterizado por un notable incremento de las publicaciones impresas, el surgimiento de los partidos políticos modernos, la abolición de la esclavitud, la expulsión de los Jesuitas 
del país, la ratificación legal de la libertad de imprenta, para finalizar con la aprobación de la Constitución de 1853. Y aunque la historiografía nacional ha abordado este período con relativa rigurosidad, hay tres aspectos que han sido poco apreciados, estos son: los escritores públicos, los partidos políticos y el asociacionismo intelectual. Los conceptos escritor público y publicista fueron usados por los neogranadinos a mediados de siglo para referirse a aquellos intelectuales que participaron en la edición y publicación de textos impresos, entre los que podemos encontrar: periódicos, folletos, hojas sueltas, libros, traducciones, entre otros. Este fue un grupo relativamente reducido (hasta el momento he contabilizado 136 individuos) pero que tuvo una incidencia muy importante en el devenir político, y por supuesto en el afianzamiento del pensamiento político nacional.

Los escritores públicos neogranadinos no tuvieron una concepción provincial ni efímera de su labor, sino que pretendieron escribir para un tiempo más amplio que su presente. No concibieron a la prensa solamente como un medio para presentar información de los hechos cotidianos, ni para lo momentáneo y la rapidez analítica, sino que también la pensaron como la tribuna intelectual donde se gestaba el pensamiento que forjaría la democracia. Eran tan optimistas sobre el potencial transformador de la prensa, y de la imprenta en general, que creían que el impacto de sus escritos iba a ser trascendental y que la labor del publicista tenía una gran relevancia social, política e intelectual ${ }^{2}$.

La participación de los escritores públicos en la política colombiana ha sido un tema importante en la historiografía nacional, ya que los historiadores se han detenido a estudiar a los letrados desde distintas perspectivas en diferentes periodos. Renán Silva por ejemplo en Cultura escrita, historiografía y sociedad en el Virreinato de la Nueva Granada, exploró las relaciones entre los autores y lectores del periódico Papel periódico ilustrado de Bogotá, y también la relación entre el proceso intelectual y político de finales del siglo XVIII. Inquietudes intelectuales similares

2 Los Redactores del Clamor, “¿Hay patriotismo en los rojos...?”, El Clamor Nacional, Popayán, 19 de abril, 1851, 118; “El ciudadano”, El Ciudadano, Popayán, 13 de mayo, 1848: 1. Para profundizar acerca del vínculo entre política y prensa en Colombia ver: Isidro Vanegas, Todas son iguales: Estudios sobre la democracia en Colombia (Bogotá: Universidad Externado de Colombia, 2011), 223-268. 
llevaron a Sergio Mejía a estudiar La bistoria de la revolución de Colombia de José Manuel Restrepo, a partir de ese estudio, Mejía logró mostrar en La Revolución en letras, las vicisitudes a las que se enfrentó un letrado en el siglo XIX, y cómo el contexto político logró incidir en la producción intelectual. Por su parte, Patricia Cardona enfocó su estudio sobre el interés de los letrados neogranadinos, especialmente de José Antonio de Plaza, por estudiar la historia del país, además, caracterizó los distintos tipos de publicaciones destinados a variados públicos lectores. Asimismo, Rafael Acevedo orientó su investigación sobre la producción y distribución de libros en la provincia de Cartagena durante gran parte del siglo XIX, aportando elementos importantes para la caracterización de los distintos actores de los procesos intelectuales. Finalmente, sobresale la obra de Gilberto Loaiza, quien, en varios textos, pero, sobre todo, en El Poder Letrado, caracterizó a los letrados colombianos de los siglos XIX y XX. Aunque estos trabajos constituyen en conjunto, un aporte importante a la historiografía colombiana en su vertiente intelectual, aún quedan muchos temas y periodos inexplorados, es ahí donde el presente artículo busca hacer una contribución a esa rama del saber ${ }^{3}$.

En efecto, los publicistas neogranadinos a mediados del siglo XIX entendieron que los principios de la Ilustración no serían desarrollados ni difundidos si seguían actuando aisladamente. Les era necesario converger en un colectivo para que a través de la discusión pública la razón tomara un lugar preponderante en la política ${ }^{4}$. Aquellos escritores públicos, por lo tanto, se enfrentaron al reto de definir los mecanismos de discusión y difusión de su pensamiento, pues necesitaban trascender del escenario privado al ámbito público, encontrando que era la comuni-

3 Renán Silva, República Liberal, intelectuales y cultura popular (Medellín: La Carreta Editores E. U., 2005); Sergio Mejía, La revolución en letras. La historia de la revolución de Colombia de José Manuel Restrepo (1781-1863) (Bogotá: Universidad de los Andes - Universidad EAFIT, 2007); Patricia Cardona, "Historia, tradiciones editoriales y sociedad. las Memorias y el Compendio de José Antonio de Plaza (Nueva Granada, 1850)", Historia Crítica, No 57 (2015): 97-116; Rafael E. Acevedo P., "Hombres de letras en la provincia. Producción y comercio de libros en la República de Colombia, 1921-1874”, Anuario Colombiano de Historia Social y de la Cultura Vol. 43 No 1 (2016): 100-122; Gilberto Loaiza Cano, Poder letrado, ensayos sobre historia intelectual de Colombia, siglos XIX y XX (Cali: Programa Editorial Universidad del Valle, 2014).

4 La expansión de los impresos coincidió con el auge del asociacionismo: Gilberto Loaiza, "El Neogranadino, 1848-1857: un periódico situado en el umbral", en Disfraz y pluma de todos. Opinión pública y cultura política, siglos XVIII y XIX, eds. Francisco Ortega y Alexander Chaparro (Bogotá: Universidad Nacional de Colombia, 2012), 459-460. 
cación escrita la herramienta que les permitiría revestir a sus ideas de fuerza para que impactaran en la vida pública. El 72\% de los 136 publicistas activos entre 1848 y 1853, y contabilizados en la presente investigación, estuvieron vinculados a la edición de periódicos, porcentaje que refleja claramente la fascinación que aquellos hombres experimentaron por las publicaciones periódicas ${ }^{5}$.

Ser escritor público resultaba sumamente importante, pues a mediados de siglo se asistió a un fuerte interés por racionalizar la política, es decir, por hacer de aquel ejercicio el resultado de reflexiones profundas y duraderas, y no de pasiones desenfrenadas. En este contexto la prensa logró acomodarse como un instrumento de división o legitimación social, es decir, revistió de una autoridad casi inobjetable a los escritores públicos, quienes argumentaron constantemente que solo actuaban guiados por el ideal de la razón y la libertad.

Este texto toma como sujeto colectivo a los publicistas o escritores públicos en su dimensión política, por dos motivos. El primero porque no pretende ser una biografía intelectual de uno, o de los más reconocidos publicistas, y segundo porque aquellos hombres estuvieron "involucrados en una complicada red de fenómenos, ideas y situaciones" comunes de la cual les resultaba imposible escapar. Es decir, por más que alguno de estos publicistas hubiera querido desmarcarse del ambiente intelectual, no lo logró, pues sus intervenciones estuvieron ceñidas al panorama general, a las ideas proclamadas por otros publicistas, en otras palabras, cada pensamiento individual estuvo determinado por el desarrollo de unas ideas comunes y, por lo tanto, de un pensamiento nacional. Al ser este un proceso colectivo es difícil encontrar a alguien que haya sobresalido por encima de las ideas y mucho menos de las ideas hechas partido político.

$5 \quad$ Isidoro Amaya Laverde, Apuntes sobre bibliografía colombiana (Bogotá: Imprenta de Vapor de Zalamea Herrán, 1882); Joaquín Ospina, Diccionario biográfico y bibliográfico de Colombia, Tomo II y III (Bogotá: Editorial Águila, 1927); Javier Mejía Cubillos, Diccionario biográfico y genealógico de la élite antioqueña y viejocaldense. Segunda mitad del siglo XIX y primera del XX (Pereira: Sello Editorial Red Alma Mater, 2012); Gustavo Arboleda, Diccionario biográfico y genealógico del antiguo departamento del Cauca (Bogotá: Biblioteca Horizontes, 1962).

6 Gordon S. Wood, La Revolución Angloamericana como revolución (Bogotá: Ediciones Plural, 2019), 45. 
A mediados de siglo los escritores públicos se vuelcan sobre su sociedad, sobre ellos mismos para luego reinventarse a partir de unos partidos políticos con principios claros, establecidos y ampliamente difundidos, también a partir de una nueva constitución, la de 1853, que trajo consigo el sufragio universal masculino, por ende nuevas formas de representación, pero sobre todo a partir de ellos mismos, de hombres dedicados a las actividades intelectuales sin descuidar las políticas, siempre con el interés de forjar un nuevo ideal de hombre público. Este texto se divide en dos partes, en la primera se estudia a la prensa como forjadora de un nuevo tipo de escritor público. La segunda sección reflexiona sobre las distintas facetas que los escritores públicos desarrollaron en la vida política neogranadina entre 1848 y 1853.

\section{LA PRENSA, ESPACIO DEFINIDOR DEL ESCRITOR PÚBLICO}

La guerra de papeles, para usar la expresión de José Eusebio Caro, había llegado a finales de 1849 a un nivel de radicalidad que sorprendía a los mismos publicistas, pues algunos consideraban que las discusiones en la prensa se concentraban en los acontecimientos que habían envuelto a la elección del 7 de marzo de $1849^{7}$. Estas tensiones ampliaron la división de la opinión pública en dos bandos. Por un lado, los conservadores que criticaron aquella elección y difundieron su percepción acerca de la ilegitimidad del gobierno, y del otro lado, los liberales que definieron aquel acto como la primera elección verdaderamente popular. Lo cierto es que buena parte de los publicistas jóvenes calificaron aquel debate como un estancamiento de la política y un alejamiento de los letrados de los problemas en verdad importantes. En este contexto, los editores del Sur-Americano propusieron un pacto a los publicistas en general. Aquel convenio consistía en que quienes lo aceptaran se comprometían a "proceder en la discusión con franqueza, con hidalguía, y uso de un

\footnotetext{
$7 \quad$ El 7 de marzo de 1849 es una fecha muy importante para la historia colombiana, porque luego de que en las elecciones del año anterior ningún candidato lograra el número de votos necesario para ser proclamado presidente de la república, el congreso se reunió en Bogotá para culminar aquella elección. Intimidados por las sociedades de artesanos liberales, los legisladores efectuaron la elección resultando vencedor el liberal José Hilario López. Aquella elección tuvo una relevancia que trascendió en el tiempo, siendo impugnada por los conservadores, y recordada con regocijo por los liberales durante la segunda mitad del siglo. Sobre el viraje radical que vivió la prensa después de aquella elección, ver: Andrés Jiménez Ángel, "Intelectuales, política y religión en Colombia en el siglo XIX: José Manuel Groot y los escritores católicos”, Historia y Sociedad No 31 (2016): 304.
} 
lenguaje decente y comedido, para que la fría razón pueda resolver la discusión, y para que no se despierten y agiten las pasiones". Aquel pacto puede entenderse en un contexto más prolongado, pues los liberales que lo propusieron tenían la intención de modificar las prácticas políticas, racionalizando el ejercicio de la política, dando así prelación a la razón ${ }^{8}$.

La imprenta era el principal órgano de la opinión pública, según los editores del Día, pues le daba vida a la prensa periódica, es decir, le otorgaba la posibilidad de expresión a los ciudadanos, y fortalecía otros mecanismos de intervención pública como: los partidos políticos y las asociaciones civiles, que intervenían principalmente a través de sus periódicos. Puesto que la prensa, además, debía propagar los principios de la civilización y la razón entre los ciudadanos, la imprenta no era algo de lo que se pudiera prescindir en el nuevo régimen?.

Aquella exaltación de la imprenta y por supuesto de la libertad de pensamiento fue concomitante con el auge de las publicaciones impresas en la Nueva Granada -al menos 261 periódicos entre 1847 y 1854, según el Catálogo de la Biblioteca Nacional- ${ }^{10}$, hecho que tuvo relación a su turno con un incremento de los publicistas y su consolidación como protagonistas en la escena pública ${ }^{11}$. Aunque un buen porcentaje de la prensa se concentró en Bogotá (48,2\%), puede decirse que el fenómeno de la expansión de este tipo de impresos fue nacional, puesto que en otras ciudades como Cartagena, Medellín, Cali o Santa Marta también se publicaron periódicos, siendo estos el 51,8 \% (135 periódicos) del total de 261 publicaciones ${ }^{12}$. En lo referente a la duración,

8 José Eusebio Caro, "Remoción del Sr. José Eusebio Caro, uno de los Redactores de la Civilización, del destino de Contador general", La Civilización, Bogotá, 13 de septiembre, 1849, 24-25; "A la cuestión”, El Sur-Americano, Bogotá, 4 de octubre 1849, 1-2.

9 Los periódicos jugaron un rol vinculante entre los partidos y los electores, reforzando así la noción de ciudadanía: Eduardo Posada Carbó, "Newspapers, politics, and election in Colombia, 1830-1930", The Historical Journal Vol. 53 (2010): 952-962. Sobre la relación entre un periódico y las asociaciones y los partidos políticos, ver: Gilberto Loaiza, El Neogranadino, 449.

10 Catálogo de publicaciones seriadas siglo XIX (Bogotá: Biblioteca Nacional de Colombia, t. 1, v. 1 y 2., 1995).

11 "El Día", El Día, Bogotá, 22 de enero, 1848, 1. Sobre la prensa artesana a mediados de siglo, ver: Gilberto Loaiza, Poder letrado. Ensayos sobre historia intelectual de Colombia, siglos XIX y XX (Cali: Programa editorial Universidad del Valle, 2014), 83-87.

12 Una descripción de la prensa publicada en Cali puede verse en: Margarita Pacheco, "Escribiendo para el pueblo: La prensa liberal en Cali 1848-1854”, Historia y Espacio No 15 (1994): 29-30. Sobre la prensa antioqueña ver: Juan Camilo Escobar, "Impresos, periódicos en Antioquia durante la primera mitad del siglo XIX. Espacios de sociabilidad y de opinión de las élites letradas” en Disfraz y pluma 
estas empresas intelectuales no pudieron perdurar en el tiempo, pues del total de periódicos solamente 14 pudieron durar más de 5 años, mientras un gran número, 170, se publicaron durante un año o menos, los siguientes gráficos clarifican estos datos.

\section{Gráfica No. 1}

Publicaciones periódicas en la Nueva Granada - fundadas entre 1847-1854

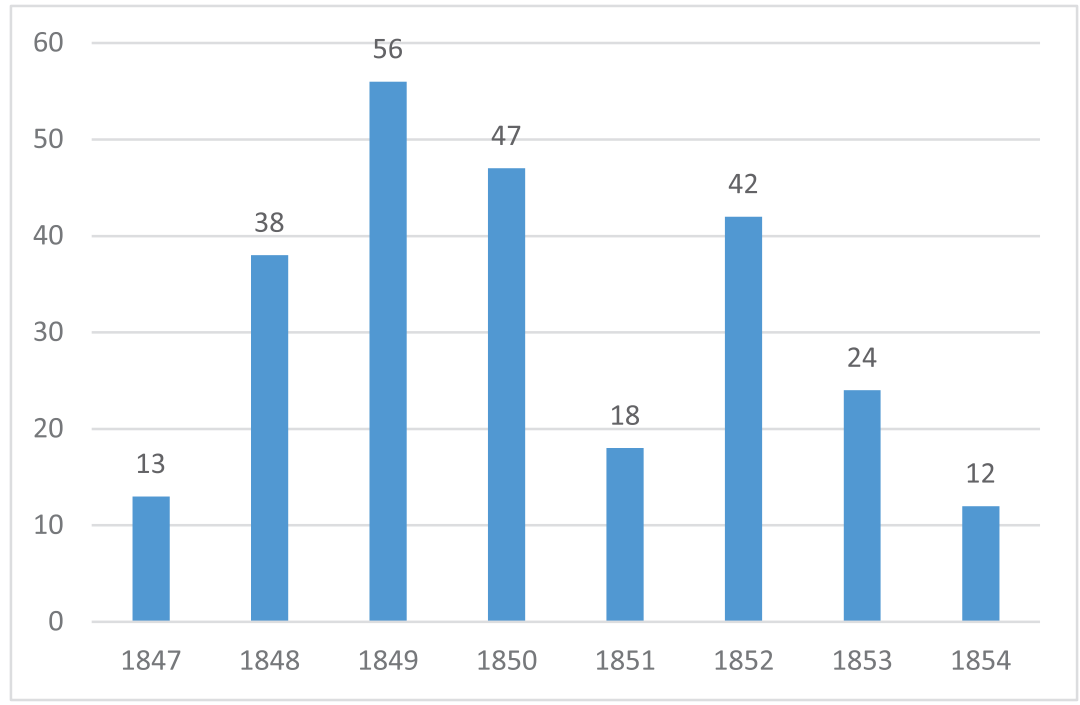

Fuente: Catálogo de publicaciones seriadas siglo XIX.

Gráfica No. 2

Duración de los periódicos (en años)

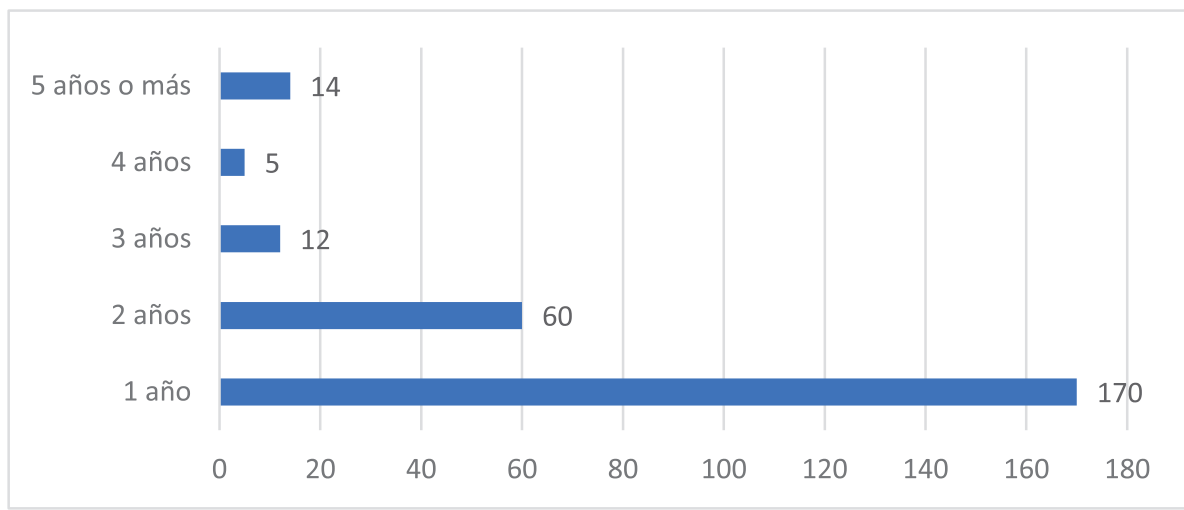

Fuente: Catálogo de publicaciones seriadas siglo XIX

de todos. Opinión pública y cultura política, siglos XVIII y XIX, eds. Francisco Ortega y Alexander Chaparro (Bogotá: Universidad Nacional de Colombia, 2012), 519-523. 


\section{Gráfica No. 3}

Distribución de periódicos por ciudades (1847-1854)

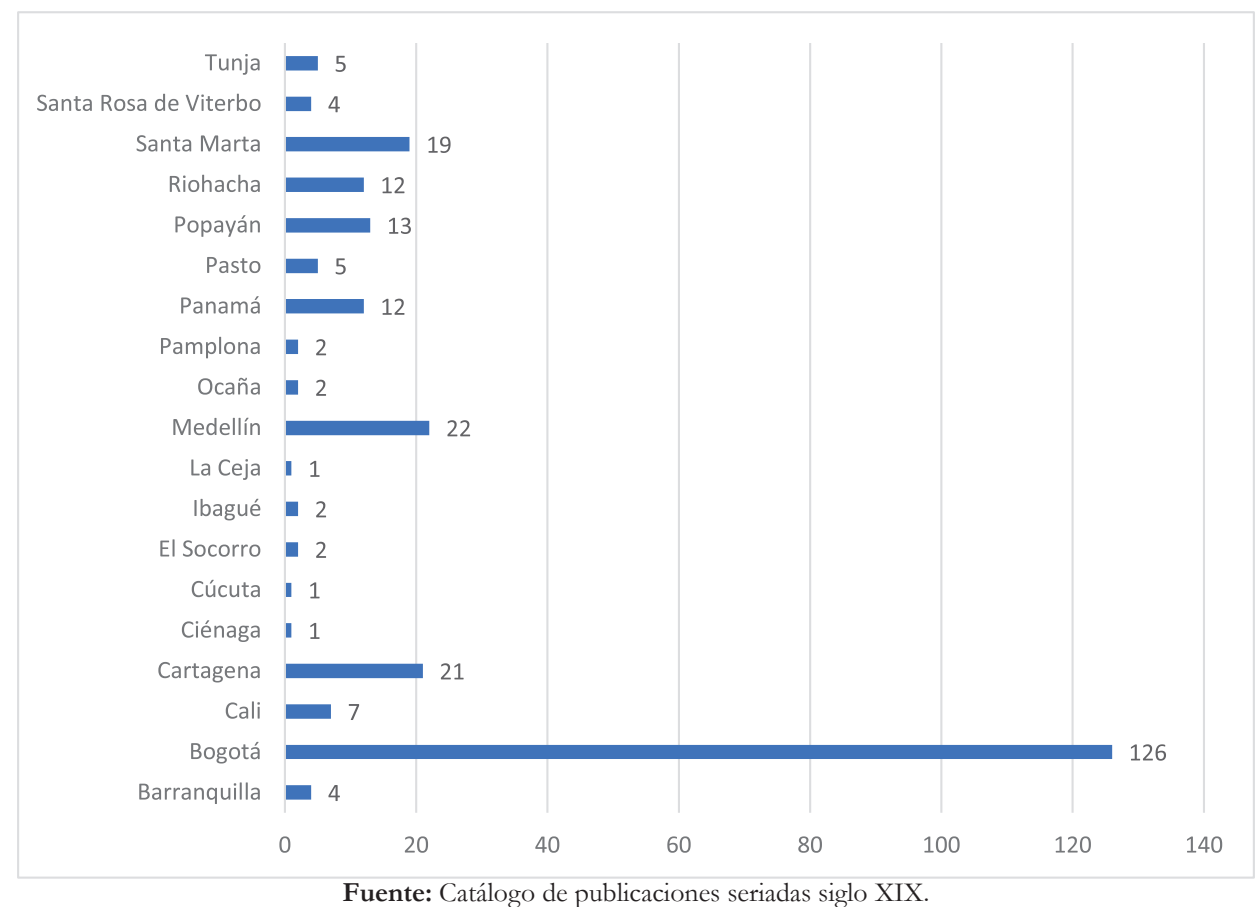

Tal situación entusiasmó a los publicistas liberales del Aviso, que reconocieron que el aumento de los impresos, incentivó la producción bibliográfica, lo cual vieron como preludio de un orden estable y de paz pública, como si la república por fin estuviera en el camino de la civilización ${ }^{13}$. Algunos publicistas no solo pensaron que la creatividad intelectual garantizaba la tranquilidad política, sino que la nueva generación de escritores públicos había sido criada bajo el principio de la libertad, y a diferencia de las generaciones precedentes no tenía los vicios del absolutismo. Muchos pensaron, igualmente, que su generación era el fruto del afianzamiento del ideal democrático a nivel mundial, cuya mejor muestra era la Revolución Francesa de 1848, lo que sin duda - pensaban los publicistas neogranadinos- reafirmaba la justeza de la democracia. En este nuevo escenario fue donde un amplio

13 "Publicaciones nuevas", El Aviso, Bogotá, 28 de diciembre, 1848, 2-4. Sobre la evolución de las publicaciones impresas en la primera mitad del siglo XIX: Alfonso Rubio y Juan David Murillo, Historia de la edición en Colombia 1738-1851 (Bogotá: Instituto Caro y Cuervo, 2017): 141-309. 
y marcadamente joven grupo de escritores públicos, pues su promedio de edad fue de 25 años, llegó a tener en la escena pública unas repercusiones inéditas. A ellos, los editores liberales del Siglo los denominaron como "los sacerdotes de la civilización", pues su tarea era difundir el ideal democrático e incentivar la práctica de los valores inherentes a este régimen político. El de los escritores públicos, pues, no era un rol secundario, porque quienes se dedicaban a las letras tenían que asumir el mejoramiento intelectual de la nación, pues la democracia era considerada como el resultado de la difusión de las luces, es decir, solo un pueblo ilustrado podía alcanzar aquel ideal ${ }^{14}$.

Ese optimismo, sin embargo, no lo compartieron publicistas como el conservador José Eusebio Caro, pues, aunque elogió a la imprenta, por facilitar la difusión de las ideas ilustradas y ser el instrumento más idóneo para transmitir el pensamiento mediante su fijación por la escritura, advirtió que ella también era capaz de propagar la mentira y la calumnia. En las ideas que la prensa difundía, dijo, podían estar "las caretas risueñas del sofisma, las linternas sin luz de la falsedad, los puñales acerados de la injuria". Es decir, las ideas que difundía la prensa eran armas intelectuales que vigorizarían a una sociedad o la hundirían en la desolación, por eso le preocupaba que la proliferación sin control de los impresos desestabilizara el orden público. Al pensamiento escrito, dijo, "vienen a buscar los partidos políticos sus armas, las armas a que respectivamente se hallan habituados". En otras palabras, la prensa se usaba en función de los valores que cada escritor público profesaba, lo que sin duda inquietó a este conservador ${ }^{15}$.

Aunque también reconocieron la importancia de una prensa dinámica como incentivo para la participación ciudadana en los asuntos públicos, los publicistas conservadores de La Civilización se mostraron preocupados en 1850 ante la debilidad de la opinión pública, pues creían que aún su impacto era muy frágil, porque la sanción social que podía efectuar era casi nula. Según ellos, la fuerza de la opinión pública radicaba en su "uniformidad y generalidad", pero en el país los periódicos se habían

14 "Prospecto", El Siglo, Bogotá, 8 de junio, 1848, 1-2.

15 José Eusebio Caro, "La Polémica de los rojos", La Civilización, Bogotá, 4 de octubre, 1849, 35-37. 
confinado a disputas y polémicas entre ellos, lo que daba la sensación de que habían relegado las cuestiones políticas e intelectuales. Además, en el país aún se imprimía y se leía poco, por lo que la prensa y los escritores públicos carecían de influencia sobre la sociedad, contrariamente a lo que sucedía en Inglaterra o los Estados Unidos ${ }^{16}$.

El liberal Juan de Dios Restrepo (seudónimo: Emiro Kastos) coincidió en afirmar que la prensa neogranadina era infecunda, pues las pasiones sectarias habían hecho de ella un lugar donde las ideas se disecaban y perdían su utilidad. Los personalismos, precisaba, se habían tomado las páginas de los periódicos, reduciendo su objetivo a "provocar antipatías y recalentar pasiones". Los temas literarios, industriales, artísticos o científicos habían sido relegados por los odios de partido. En medio del escepticismo de este antioqueño, salió a la luz pública una obra innovadora intelectualmente, pues mezcló los atributos de los relatos de costumbres con el ensayo, dando como resultado los pasajes de $L a$ Peregrinación de Alpha, que publicó El Neo-Granadino entre 1850 y 1851, escrito que Restrepo elogió por su Ilustración y por separarse de los odios partidarios para ofrecer un relato que sería difícil inscribir en un solo estilo literario, pero que sin duda expuso claramente elementos sociales, culturales y económicos del país, para ese entonces bastante desconocido. Textos de ese tipo tenían una importancia mayúscula en la orientación de las prácticas gubernamentales, pensaba el liberal, pues instruían a la opinión pública sobre las necesidades y posibilidades económicas y sociales en las distintas partes del territorio nacional ${ }^{17}$.

Otros liberales, también fueron pesimistas sobre el estado de la actividad periodística en el país, pues en comparación con España, por ejemplo, resultaba diminuta, dado que solo en Madrid se publicaban 69 periódicos, mientras en Bogotá solamente había 7 periódicos de publicación constante. A los editores de El Pasatiempo les asombró más aún este dato porque consideraban a España la parte más atrasada de Europa. Concluían que en el país se hacían periódicos "sin método, sin plan, sin sistema, y solamente como de paso, y por no hacerles el desaire" a

16 “Opinión pública”, La Civilización, Bogotá, 8 de agosto, 1850, 200.

17 Emiro Kastos, "Alpha”, El Neo-Granadino, Bogotá, 17 de octubre, 1850, 356-357. 
las tareas de la Ilustración. Si en España no existía una ley que garantizara la libertad total de imprenta como sí sucedía en la Nueva Granada en 1852, no eran las constituciones o las leyes las que impulsaban la actividad periodística, concluyeron; sino que "lo que principalmente determina este elemento de vida social y lo desarrolla prodigiosamente es la paz, el espíritu de industria, de trabajo y de asociación"18. El también liberal editor del Sur-Americano afirmó que a pesar del incremento de las publicaciones periodísticas, el país estaba en un letargo intelectual, una de cuyas causas radicaba en que los escritores públicos se dedicaban a "discusiones que casi exclusivamente se versan sobre personas y no sobre principios". Criticó, por lo tanto, el culto a la personalidad que inspiraba la publicación de algunos periódicos, pues así se demeritaba a la prensa como actividad intelectual ${ }^{19}$.

No obstante, fue común pensar que la labor periodística era imprescindible para vigorizar la república y por ello debía servir para la consolidación de ciertos valores. Para Florentino González, la coexistencia de los escritores públicos de todas las tendencias era necesaria para que en el país se consolidara la democracia, por lo que consideraba paradójico que muchos publicistas no se dedicaran sino a denigrar de los escritores políticamente adversarios, dejando de lado su labor intelectual. Afirmaba que los periódicos que habían surgido con el único interés de criticar, y no producir ideas, solo mostraban la incapacidad intelectual de sus editores. Finalmente, González advertía que en algunos casos las críticas eran producto de la ignorancia, porque los impugnadores lo hacían sin haber leído o reflexionado las ideas a las que se referían ${ }^{20}$.

Para otros publicistas el patriotismo era el valor más importante, pues era la brújula que guiaba sus acciones, y creían que la labor de control político y difusión de las luces a través de la prensa, era la mejor prueba de su interés por el progreso de la nación ${ }^{21}$. En ese sentido, un rasgo común de aquellos publicistas fue el repudio por la monarquía, pues sin

18 "El periodismo y los toros - la reconquista y los jesuitas", El Pasatiempo, Bogotá, 7 de febrero, 1852, 229.

19 "El periodismo en América", El Sur-Americano, Bogotá, 2 de diciembre, 1849, 1-2.

20 Florentino González, "Caracteres Políticos", El Neo-Granadino, Bogotá. 18 de febrero, 1853, 53-54.

21 "Situación de la república”, La América, Bogotá, 23 de abril, 1848, 21-22. 
importar que fueran conservadores o liberales insistieron en demostrar su orgullo por el republicanismo americano en oposición a las monarquías europeas, que pensaban, estaban en decadencia, como lo mostraba la Revolución Francesa de 1848, cuyos acontecimientos fueron ávidamente leídos por los publicistas neogranadinos ${ }^{22}$.

La prensa, y sus agentes, por lo tanto, no solo recibieron recriminaciones. Los editores de La América afirmaron que el estado de la prensa periódica servía de medida para juzgar el grado de adelantamiento de una sociedad, y declararon que las publicaciones impresas habían resultado "indispensablemente las más numerosas, las más importantes, y las que pueden ejercer mayor influencia en la condición y destino de los pueblos", pues a ellas estaban dedicados los mejores escritores, de modo que quien no participara en la edición de un periódico estaba rezagado intelectualmente. El origen de aquel interés radicaba en la facilidad con que se leía y se difundía un periódico, pues allí cualquier ciudadano, sin importar su profesión, podía enterarse de los acontecimientos más importantes en materia política, científica, militar o industrial; a diferencia de los folletos o los libros, que requieren del lector una predisposición más profunda para la lectura ${ }^{23}$. Una actitud similar expresó un publicista liberal en 1851 al afirmar que la imprenta lideraba la cruzada de la civilización, y que garantizar la libertad de prensa era el primer paso para asegurar la preeminencia de la civilización ${ }^{24}$. Argumentó que los escritores públicos preferían el periódico sobre el libro para difundir sus pensamientos, por considerarlo más universal, pues "no hay ninguna cuestión, ninguna tesis que el periódico no se atreva a tratar y a discutir", por lo que "en el momento que los periódicos enmudecen, se deja sentir la mano pesada del despotismo"; siendo esta una de las virtudes que justificaba la predilección de los escritores públicos por los periódicos ${ }^{25}$.

22 "La República y la Monarquía”, El Día, Bogotá, 1 de enero, 1848, 3-4.

23 "El periodismo en América", La América, Bogotá, 16 de abril, 1848, 19-20.

24 En 1851 el congreso neogranadino consolidó la libre expresión del pensamiento por medio de la prensa, la cual fue una de las reformas más relevantes del gobierno de José Hilario López y que posteriormente sería ratificada en 1853 por el texto constitucional sancionado ese año.

25 Emiro Kastos, "La imprenta, la inteligencia y la fuerza”, El Neo-Granadino, Bogotá, 26 de septiembre, 1851, 310-311. 
Los publicistas, tanto liberales como conservadores, tendieron a pensar que la prensa era fecunda si ayudaba a desarrollar las metas de su propio partido. Los editores del Neo-Granadino alegaron que en las manos correctas, es decir, en las de ciudadanos independientes, la prensa era un vehículo "magnífico y fecundo" para difundir los valores propios de la democracia, pero en manos de los partidos era un instrumento despótico que incentivaba las pasiones y crispaba el orden en las naciones. Añadían que un periódico verdaderamente patriota, "es el que se eleva a la altura de su misión republicana, que obra fuera de la esfera de los partidos, [...] que es extranjero a los sistemas como a las pasiones". Esta declaración no podía, sin embargo, eludir el hecho de que los artífices de ese periódico militaban en el Partido Liberal, lo cual se traducía en que su periódico en realidad no era y no podía ser aquel instrumento virtuoso. Por lo demás, ningún periódico neogranadino hubiera podido ser considerado patriótico según aquella exigencia, porque todos respondían a partidos políticos o a hombres públicos que a su vez integraban los partidos ${ }^{26}$. En cuanto a la filiación partidaria de aquellas publicaciones es notoria la preeminencia liberal, perteneciendo a esta corriente un $42,14 \%$, frente a un $21,07 \%$ de publicaciones conservadoras, aclarando que aún queda un 36,78 \% del total de periódicos por identificar ideológicamente ${ }^{27}$. Sin embargo, esta tendencia muestra que el vínculo entre la prensa y los partidos políticos fue inobjetable ${ }^{28}$.

Bien consideraran fecunda o estéril a la prensa, los publicistas le asignaron grandes objetivos. Algunos creyeron que con la edición de periódicos se obraba por la libertad y la felicidad del pueblo, como lo expresó "Un patriota" en 1848, que afirmó que quienes se dedicaban a aquellas labores eran "hombres animosos, inteligentes y resueltos" que tenían el coraje de publicar las iniquidades cometidas por los poderosos ${ }^{29}$. Los

26 "De la democracia en Suramérica y particularmente en la Nueva Granada", El Neo-Granadino, Bogotá, 30 de julio, 1852, 155-157.

27 Catálogo de publicaciones seriadas siglo XIX.

28 Para una caracterización de los escritores católicos, ver: Jiménez Ángel, Intelectuales, política, 305306. En temporadas electorales los periódicos tomaban partido y dejaban los otros temas en un segundo plano, ver: Eduardo Posada Carbó, Newspapers, politics, 955. Francisco Ortega y Alexander Chaparro, "El nacimiento de la opinión pública en la Nueva Granada, 1785-1830", en Disfraz y pluma de todos. Opinión pública y cultura política, siglos XVIII y XIX, eds. Francisco Ortega y Alexander Chaparro (Bogotá, Universidad Nacional de Colombia, 2012), 37-126.

29 Un Patriota, "Sr. Editor de la Gaceta mercantil", La Gaceta Mercantil, Santa Marta, 6 de septiembre, 
redactores de un periódico de Pamplona pensaron que su rol consistía en pulir las reflexiones que irían a ser debatidas en las cámaras legislativas, pues consideraban que las improvisaciones de los hombres públicos en las discusiones eran práctica rutinaria que empobrecía intelectualmente el ejercicio político ${ }^{30}$. Otros editores pensaban que el oficio del periodista debía evolucionar para ser "un popularizador de ideas, que bebe en los libros la ciencia del sabio para ponerla al alcance del mayor número y hacer su aplicación de los intereses actuales" 31 . Es decir, los escritores públicos debían ser hombres muy estudiosos, pues tenían la responsabilidad de propagar la Ilustración.

Pese a la importancia que muchos le concedieron a la prensa, la edición de un periódico en la Nueva Granada era una tarea que enfrentaba diversas dificultades, como lo relató el Charivari Bogotano, que describió la vida de los editores como "un tejido de camorras y de molestias", por varias razones. En primer lugar, debido a las penurias económicas, pues ningún editor podía vivir de aquel oficio, salvo que fuera el dueño de una imprenta. Además, debían enfrentarse a una serie de "consejeros" que entorpecían sus obligaciones editoriales porque no se sentían satisfechos con ningún tipo de publicación ${ }^{32}$. Igualmente, mantener un periódico era una tarea titánica, por la necesidad de escribir de manera constante sobre cuestiones muy diversas, por eso, publicistas como el redactor del Cuatro de Julio, periódico liberal de Pamplona, invitó a los ciudadanos "ilustrados" a enviar sus artículos sobre las materias que creyeran de interés público para nutrir las páginas de aquel periódico y evitar así la monotonía ${ }^{33}$.

1848,3 .

30 Los Redactores, "Honor al espíritu público", Suplemento a "El cuatro de julio", Pamplona, 27 de febrero, 1850.

31 "El periodismo en América", El Sur-Americano, Bogotá, 2 de diciembre, 1849, 1-2.

32 "La vida de un editor en la Nueva Granada", El Charivari Bogotano, Bogotá, 5 de noviembre, 1848, 1-2. Sobre las dificultades financieras para mantener las publicaciones periódicas en distintos periodos del siglo XIX ver: David Bushnel, "The Development of the Press in Great Colombia", The Hispanic American Historical Review Vol. 30 No 4 (1950): 445; Eduardo Posada Carbó, "¿Libertad, libertinaje, tiranía? La prensa bajo el Olimpo Radical en Colombia, 1863-1885”, en El radicalismo colombiano del siglo XIX, ed. Rubén Sierra (Bogotá: Universidad Nacional de Colombia, 2006), 152-153.

33 El Redactor, “La Redacción”, El Cuatro de Julio, Pamplona, 17 de julio, 1850, 4. 
Ulpiano González (seudónimo: Juancho Blanco), publicista liberal, manifestó en 1848 que la dificultad común que enfrentaban los escritores públicos, sin importar el género literario a que se dedicaran o la orilla política a la que pertenecieran, eran las críticas que se esgrimían contra cualquier texto o proyecto intelectual. Los escritores públicos debían tener por lo tanto un carácter preparado para enfrentar esas críticas implacables, sin importar el texto que publicaran, el partido al que pertenecieran o el cargo que desempeñaran ${ }^{34}$. Además, según González, no había estímulos para quien deseara ser periodista, pues aunque era una de las profesiones más importantes para la consolidación democrática, la nación no reconocía los beneficios de ella. Añadió que el país, por su condición de aislamiento económico, no permitía beneficios para estas empresas intelectuales, pues eran ingentes los esfuerzos que hacían quienes se involucraban en estas labores y la retribución nunca era significativa. Por eso, él se había decidido por ser un "simple" articulista, que escribía ocasionalmente sin involucrarse en la engorrosa labor de publicar un periódico ${ }^{35}$.

En conclusión, en el periodo de estudio se asistió al surgimiento de los partidos políticos como organizaciones estructuradas y a una propagación sin precedentes de la prensa. A partir de estos sucesos, surgieron nuevos actores públicos, figuras que transformaron la práctica política impulsados por el ideal de fortalecer el orden democrático y exterminar cualquier vestigio de monarquismo. Una de estas figuras fue el escritor público, que en su dimensión política fue entendido como un baluarte en el afianzamiento de las libertades democráticas, porque tenían el deber de inaugurar los debates públicos, y de hacer que el pueblo se hiciera partícipe de las cuestiones nacionales, pues, eran los encargados de propagar los programas políticos de sus respectivos partidos ${ }^{36}$. Así,

34 Juancho Blanco, "Guerra a quien la merezca", El Neo-Granadino, Bogotá, 2 de septiembre, 1848, 34-35.

35 Juancho Blanco, "No soy ni seré periodista”, El Siglo, Bogotá, 21 de septiembre, 1848, 4. Sobre las diferencias entre editor e impresor, ver: Paola Ruíz, "La libertad de imprenta en la Nueva Granada: los juicios contra El Alacrán a mediados del siglo XIX", Anuario Colombiano de Historia Social y de la Cultura Vol. 43 No. 2 (2016): 279-305.

36 Zamborondon, "A mi Juanchito", El Aviso, Bogotá, 13 de agosto, 1848, 3. Sobre el surgimiento de un nuevo tipo de intelectual asociado a la prensa periódica, ver: Hilda Sabato, "Nuevos espacios de formación y actuación intelectual: prensa, asociaciones, esfera pública (1850-1900)" en Historia de los intelectuales en América Latina, ed. Jorge Myers (Buenos Aires: Katz Ediciones, 2008), 399-408. 
los escritores públicos en general estuvieron comprometidos con la difusión de los principios políticos de sus partidos, pues creían que de esa manera enaltecían la práctica política.

\section{Facetas del escritor PÚblico}

Los "hombres honrados" eran quienes debían escribir en la prensa, pensaban en 1849 los editores de La Juventud Granadina, periódico conservador de Bogotá, puesto que eran los responsables de forjar el carácter de la nación, además creían que en las naciones democráticas el periodismo tenía dos funciones, el control político al gobierno, y la defensa ministerial de este ${ }^{37}$. En esta medida, los escritores públicos se vieron a sí mismos como jueces políticos, como lo manifestaron los periodistas del Antioqueño Constitucional, quienes apelando a sus virtudes intelectuales alegaron el derecho a controlar los actos del gobernador de la provincia de Antioquia. En la oposición, los publicistas asumían un rol de control político y al mismo tiempo esgrimían su carácter "especial" de escritores públicos para aconsejar al gobierno, como fue el caso de los conservadores José Eusebio Caro y Mariano Ospina, que enviaron una representación al presidente de la república en 1850, con motivo del proyecto de expulsión de los sacerdotes Jesuitas, que se discutía en el congreso, para sugerirle que abandonara la idea de expulsarlos dadas las consecuencias nefastas que podría tener esa decisión para la estabilidad de la república ${ }^{38}$.

A los publicistas adeptos al gobierno, además, se les asignaron dos funciones, según lo expresó el periódico conservador cartagenero La República: "defender los actos de los gobernantes demostrando su legalidad y conveniencia" e informar sobre los asuntos gubernamentales. De aquellas funciones, decía este periódico, los oficialistas solo cumplían con la primera; la segunda no la llevaban a cabo porque constantemente estaban comprometidos en polémicas con los demás

37 "La prensa desencadenada", La Juventud Granadina, Bogotá, 15 de septiembre, 1849, 3-4.

38 "Los Rojos y el Doctor Jorge Gutiérrez de Lara”, El Antioqueño Constitucional, Medellín, 29 de diciembre, 1850, 47; José Eusebio Caro y Mariano Ospina Rodríguez, "Fragmentos de una representación dirigida al ciudadano presidente de la república”, La República, Cartagena, 6 de junio, 1850, $3-5$. 
publicistas. Una de las causas de aquella situación se debió a la adulación hacia el gobierno, pues este les proporcionaba recompensas, como cargos públicos o ascensos, empobreciendo no solamente el periodismo, sino también la función gubernativa, pues decía que los secretarios de Estado se dedicaban a la publicación de periódicos con tal de seguir siendo los beneficiarios de los favores gubernamentales ${ }^{39}$.

Los hombres públicos que aspiraran al reconocimiento de sus conciudadanos tenían en la prensa un lugar para mostrar sus destrezas intelectuales. A los editores de La Gaceta Mercantil, periódico liberal de Santa Marta, les preocupaba por ello que los candidatos a la presidencia en 1848 no tuvieran el hábito de publicar sus ideas y reflexiones sobre los temas de la vida pública de la nación, pues consideraban que aquella práctica era una cualidad inherente a los hombres públicos. Esta ausencia de reflexiones escritas generaba, según aquellos editores, confusión, sospechas y juicios errados sobre las ideas y principios de los candidatos. Así se iba gestando el ideal de hombre público, el cual debía tener un vínculo estrecho con las actividades intelectuales ${ }^{40}$.

Entonces, hacia 1848 era evidente que quienes quisieran aspirar a la presidencia debían contar con el apoyo de los escritores públicos, o incluso ser uno de ellos y publicar su propio periódico, el ejemplo más claro de esta práctica fue Florentino González, que fundó El Siglo en 1848 para impulsar su candidatura a la presidencia. Esto significa que la prensa fue considerada como el principal instrumento de la civilización, el progreso y la paz, como pensaban los editores de La América. Sin embargo, afirmaban que aquel carácter ilustrado de esos impresos aún no había sido apropiado, ni desarrollado, por lo tanto, la labor del periodista constantemente era menospreciada. Aquellos editores creían que el periodismo practicado en el país tenía un carácter disociador que generaba discordias entre los ciudadanos, una práctica contraria al ideal que le habían adjudicado ${ }^{41}$.

39 “¿Para quién escriben los periódicos del ministerio y qué escriben?”, La República, Cartagena, 11 de julio, $1850,1$.

40 "Los candidatos para la presidencia y su conducta actual", La Gaceta Mercantil, Santa Marta, 24 de mayo, 1848, 4.

41 "El periodismo en América", La América, Bogotá, 16 de abril, 1848, 19-20. 
Por otro lado, una buena parte de los periodistas suramericanos desconocían su importancia en la consolidación democrática de sus naciones, pensaban, pues algunos tenían una noción momentánea de su trabajo, es decir, sus reflexiones no estaban encaminadas a perdurar. Aquellos pensamientos fueron comunes en un contexto en el que los escritores neogranadinos buscaban consolidar su labor y a la prensa como las herramientas predilectas de la civilización y el progreso. Por eso decían que los periodistas debían aprender a tratar las cuestiones políticas sin confundirlas con las personales, de entender esto dependía la consolidación del oficio del periodista como una labor ilustrada y respetable, que aportara no solo a la consolidación democrática de la nación, sino también a la ilustración popular ${ }^{42}$. En tal sentido, la función de los publicistas no se reducía a informar sobre los acontecimientos del devenir político y social de la nación, sino que aportar reflexiones sobre aquellos hechos era inherente a esa profesión. En ese mismo sentido, una publicación conservadora reconocía que la labor del periodista no podía cubrirse con un falso velo de objetividad, pues los periodistas no podían esconder sus simpatías hacia personas o ideas ${ }^{43}$.

En síntesis, aquella profesión fue entendida como trascendental para el afianzamiento democrático de la nación. Según los editores del Siglo "la misión de los periodistas es moralizar, no corromper a sus compatriotas”, porque en comparación con las demás profesiones, su labor era vista, analizada y replicada por el conjunto social, de ahí que el mal ejercicio de aquel oficio condujera a la fragmentación social ${ }^{44}$.

Un publicista que aspiraba a un reconocimiento público debía tener la capacidad de asumir, llegado el caso, responsabilidades administrativas. Así, en 1850 los editores del periódico liberal La Democracia, validaron la capacidad de Manuel Murillo Toro para desempeñarse como secretario de hacienda, nombramiento que había sido fuertemente impugnado por la prensa conservadora, que lo consideraba inexperto para tal cargo.

42 "El periodismo en América" 19-20.

43 "El trece de junio", La América, Bogotá, 18 de junio, 1848, 63-64; "El Día”, El Día, Bogotá, 21 de junio, 1848, 2; “El 7 de marzo de 1849”, La Democracia, Cartagena, 7 de marzo, 1850, 1.

44 “QQuién debe ser electo presidente de la Nueva Granada?”, El Siglo, Cartagena, 22 de junio, 1848, $1-3$. 
Sus copartidarios recordaron su labor como escritor público, en la que se había dedicado a estudiar y a escribir sobre asuntos financieros, afirmando que esa era experiencia suficiente para desempeñar dicho puesto ${ }^{45}$.

Combinar la faceta de periodista y la de funcionario público siempre fue problemático, pues quienes desempeñaban estas labores simultáneamente, eran impugnados por sus contendores políticos porque supuestamente perdían su independencia al devengar un salario del gobierno. Por ello, Florentino González criticó en 1853 la oposición de los editores de La Discusión al proyecto federalista que empezaba a ser discutido con más intensidad en la prensa, exhortándolos a asumir una actitud independiente, y recordándoles que su periódico había surgido bajo el auspicio gubernamental, pero que era hora de desprenderse de aquel vínculo. A ello contestaron los editores de La Discusión que era normal que los gobiernos democráticos tuvieran sus escritores para que los vindicara ante la opinión pública, y aludieron a los Estados Unidos para reforzar su respuesta, pues el gobierno de aquel país no solo sostenía periódicos ministeriales, sino que publicaba constantemente folletos y libros para explicar las reformas adelantadas o las que se adelantarían, e incluso quienes escribían en estas publicaciones eran los ministros o secretarios del despacho. Terminaron diciendo que cuando las críticas al gobierno eran vagas e injuriosas, él estaba en su derecho de defenderse con la razón y la ilustración propias de la imprenta ${ }^{46}$.

La actividad intelectual de los hombres públicos, sin duda era un capital importante para sus pretensiones de lograr un puesto o una responsabilidad en el gobierno, como lo reconoció en 1850 el liberal Joaquín Pablo Posada, que el año anterior había editado El Alacrán, periódico satírico que había proclamado su completa autonomía con todas las fuerzas políticas y cuya intención había sido burlarse de los hombres públicos ${ }^{47}$. Posada fue nombrado contador secundario de la nación en

45 "El Dr. Manuel Murillo, secretario de hacienda”, La Democracia, Cartagena, 1 de agosto, 1850, 2.

46 Florentino González, "Un lugar común impugnado por segunda vez”, El Neo-Granadino, Bogotá, 28 de enero, 1853, 28-29; “La discusión”, La Discusión, Bogotá, 19 de febrero, 1853, 1-2.

47 Los editores de El Alacrán Joaquín Pablo Posada y Germán Gutiérrez de Piñeres fueron acusados, en 1849, por delitos políticos y de injuria, debido al contenido de ese periódico, ver: Paola Ruíz, La libertad de imprenta, 284-294. 
1850, nombramiento que criticó José Eusebio Caro, editor de La Civilización, ante lo cual Posada manifestó su arrepentimiento por haber participado en la edición de aquel periódico, que calificó de arrebato juvenil. Con este caso se puede ver el cambio en la mentalidad de los escritores públicos, aunque esta variación estuvo mediada por factores externos, como el nombramiento en un cargo público. Además, el editor de La Civilización creyó que Posada había editado El Alacrán para lograr un reconocimiento ante la opinión pública y un puesto en el gobierno, y si lo vemos desde esta perspectiva, aquella estrategia funcionó ${ }^{48}$.

Las campañas eleccionarias fueron otro escenario en el que por su carácter los publicistas desempeñaron un rol preponderante, pues ellos estaban en capacidad de discriminar negativamente a algún candidato o de ayudar a la construcción de alianzas entre facciones partidistas, lo cual resultaba importante en 1848, pues al carecer los partidos de estructuras claras, las candidaturas seguían siendo personalistas. Los candidatos a diversos cargos, por lo tanto, establecieron fuertes vínculos con los publicistas y sus publicaciones ${ }^{49}$. El vínculo que se dio entre escritores públicos y partidos políticos se pone de presente cuando se observa que solo el $6 \%$ de los publicistas entre 1848 y 1853 carecieron de algún vínculo con los partidos políticos, mientras que el restante $94 \%$ se repartió en un $27 \%$ de publicistas conservadores y $67 \%$ de liberales ${ }^{50}$.

La participación de la prensa y los periodistas en las elecciones se daba en diversos momentos, por lo que el publicista conservador Manuel María Madiedo diferenció dos etapas eleccionarias. La primera, correspondía a la discusión, en la que la prensa y las asociaciones tenían preponderancia, y en la que no era propio hablar de sentimientos nacionales, pues se dejaban predominar los intereses partidarios. En la segunda etapa, el protagonismo correspondía a la urna electoral, y allí la discusión daba

48 Joaquín Pablo Posada, "Cobardía”, El Neo-Granadino, Bogotá, 4 de mayo, 1850, 145; "Nuevos medios de Gobierno inventados por los hombres del 7 de marzo", La Civilización, Bogotá, 25 de abril, $1850,152$.

49 Posada Carbó, "Newspapers, politics", 952-962.

50 Isidoro Amaya Laverde, Apuntes sobre bibliografía; Joaquín Ospina, Diccionario biográfico y bibliográfico, Tomo II y III; Javier Mejía Cubillos, Diccionario biográfico y genealógico; Gustavo Arboleda, Diccionario biográfico y genealógico. 
paso a la resignación de los vencidos, y el sentimiento partidario al patriótico. Por eso mientras no se pasara a la segunda etapa, los publicistas estaban en libertad de opinar y apoyar a su candidato preferido ${ }^{51}$.

Aparte de su intervención en las formas anteriormente mencionadas, los publicistas participaron en los conflictos bélicos, tanto en la preparación de los ánimos como en los combates propiamente dichos. Los escritores públicos conservadores fueron acusados por el gobierno liberal, en medio de la guerra civil de 1851, de haber fraguado en sus imprentas y publicaciones aquel conflicto que el gobierno denominó por ello "revolución de las opiniones" o "revolución de las ideas", acusación que conllevó la persecución de las imprentas y de los editores de los periódicos conservadores ${ }^{52}$. Del lado de los conservadores, varios publicistas, como Julio Arboleda, pero también los jóvenes filotémicos ${ }^{53}$, se incorporaron de alguna manera a la rebelión armada ${ }^{54}$. Los escritores liberales, por su parte, no se quedaron al margen de la contienda bélica de 1851, y convirtieron a la Escuela Republicana en un destacamento militar, pues al fin y al cabo, como dijeron los redactores de La Reforma en julio de ese año: "Estamos en medio de una revolución: revolución de ideas, revolución de armas a la vez" ${ }^{25}$. Bajo estas premisas, la Escuela Republicana formó un cuerpo militar dentro de la Guardia Nacional "con el objeto de defender las instituciones patrias y resistir el ataque de los rebeldes" $" 56$.

Los publicistas intervinieron en la escena pública igualmente mediante su aporte a la creación y fortalecimiento de las sociedades de ideas. Ellas, dijeron los editores de La Democracia, "son el taller en que deben

51 Manuel María Madiedo, “¿Cuándo seremos verdaderos republicanos!”, El Pasatiempo, Bogotá, 5 de mayo, 1852, 357-358.

52 “iiRevolución!!!”, La Civilización, Bogotá, 13 de junio, 1851, 381. Los conservadores bogotanos alegaron que les estaban negando el ejercicio de la libertad de imprenta. La Civilización denunció que la residencia de su editor había sido allanada por las fuerzas de choque gubernamental -las sociedades democráticas-, que deseaban asesinarlo. Denunciaron también el allanamiento de la imprenta de El Día, con la justificación de que salían de allí "los proyectiles" más peligrosos para la estabilidad del orden público, ver: "Libertad de imprenta”, La Civilización, Bogotá, 20 de marzo, 1851, 333-334.

53 Los denominados "filotémicos" fueron jóvenes de ideas conservadoras que se agruparon en la Sociedad Filotémica entre 1850 y 1851.

54 "Servicio público", La Reforma, Bogotá, 27 de julio, 1851, 3.

55 "La Reforma", La Reforma, Bogotá, 20 de julio, 1851, 1.

56 "Servicio público", La Reforma, 3. 
trabajar los hombres de partido en beneficio de sus principios políticos". En estas organizaciones, que tenían como finalidad ejercitar la oratoria y perfeccionar los principios políticos, los ciudadanos mantenían activa la democracia, la perfeccionaban, por eso a mediados de siglo se vio un incremento considerable en las asociaciones de distinto tipo en el territorio nacional, siendo este el momento en que los publicistas vieron quizá con más optimismo el asociacionismo como instrumento de consolidación de las instituciones democráticas ${ }^{57}$.

Los escritores públicos simultáneamente se interesaron en la escritura de obras intelectuales más elaboradas. Y aunque publicar en la Nueva Granada un libro era una tarea engorrosa, a mediados de siglo un número considerable de hombres de letras se interesaron en escribir sobre la historia de la nación, de ahí que se hubieran publicado varios libros sobre el tema en que tanto liberales como conservadores quisieron plasmar su percepción del pasado de la nación ${ }^{58}$. Secciones de algunos de estos trabajos fueron publicados en la prensa para incentivar su venta, como sucedió con Historia de la Nueva Granada de José Antonio de Plaza, que en un primer momento fue publicada por La Gaceta Mercantil y rápidamente suscitó elogios de otros periódicos ${ }^{59}$. Esta y otras obras muestran el interés de los escritores públicos de mediados de siglo por narrar el surgimiento de la nación republicana, vigorizando con ello los cambios que deseaban impulsar, no solo a través de una completa reforma constitucional sino también con un trabajo intelectual ambicioso ${ }^{60}$. Esta

57 "Hombres de partido (segundo artículo)", La Democracia, Cartagena, 27 de junio, 1850, 1.

58 Algunos libros sobre la historia nacional publicados en el periodo: Joaquín Acosta, Compendio histórico del descubrimiento y colonización de la Nueva Granada en el siglo décimo sexto (París: Imprenta de Beau, 1848); José Antonio Plaza, Compendio de la historia de la Nueva Granada, desde antes de su descubrimiento, hasta el 17 de noviembre de 1831 (Bogotá: Imprenta del Neo-Granadino, 1850); José Antonio Plaza, Memorias para la historia de la Nueva Granada desde su descubrimiento hasta el 20 de julio de 1810 (Bogotá: Imprenta del Neo-Granadino, 1850); Tomás Cipriano de Mosquera, Memoria sobre la geografía física y política de la Nueva Granada (Nueva York: Imprenta de S. W. Benedict, 1852); José María Samper, Apuntamientos para la historia política y social de la Nueva Granada (Bogotá: Imprenta del Neo-Granadino, 1852). Para profundizar en el interés por escribir y difundir la historia ver: Patricia Cardona, Historia, tradiciones editoriales, 104-108.

59 Sobre edición, publicación y comercialización de libros en la provincia de Cartagena durante gran parte del siglo XIX, ver: Rafael E. Acevedo P., Hombres de letras en la provincia, 100-122.

60 "Estímulos", El Aviso, Bogotá, 24 de septiembre, 1848, 2; "Una publicación histórica", El Día, Bogotá, 13 de septiembre, 1848, 2; "Historia de la Nueva Granada", El Nacional, Bogotá, 21 de octubre, 1848, 1; "Historia de la Nueva Granada desde su descubrimiento hasta el 20 de julio de 1810", La Gaceta Mercantil, Santa Marta, 16 de agosto, 1848, 2-3. 
búsqueda llevó a los publicistas a preocuparse por su estilo de escritura y a tratar de refinar el lenguaje, a intentar hacer el mejor uso posible en sus publicaciones, pero también a estimular el buen uso del idioma en la sociedad neogranadina. En ese sentido, Ulpiano González pensaba que la formación de sociedades literarias dedicadas al estudio del lenguaje, las cuales publicarían periódicos dirigidos a la juventud como parte de su labor, era una buena estrategia para sofisticar el lenguaje usado en el país, el cual consideraba burdo y falto de elegancia ${ }^{61}$. González también publicó, en 1848, Observaciones curiosas sobre la lengua castellana, una propuesta pedagógica para que en las escuelas primarias se mejorara el uso del idioma ${ }^{62}$.

En conclusión, fue común que los publicistas consideraran que si el nivel de educación política de las masas populares neogranadinas estuviera acorde con el andamiaje constitucional, los escritores públicos no tendrían que involucrarse tan profundamente en la propagación de los programas y las ideas políticas, y podrían desarrollar actividades intelectuales destinadas a alcanzar el anhelado progreso nacional. Pero como ellos alegaron que esa no era la realidad, sino que había una ignorancia generalizada en materia política y que se hacía más evidente en las temporadas eleccionarias, los escritores necesariamente se involucraron en las luchas partidarias, carentes, según muchos, del decoro de la labor intelectual, pues implicaban reyertas inútiles e infértiles intelectualmente para hacerse de los votos populares ${ }^{63}$.

\section{Conclusiones}

Desde los albores del régimen democrático la prensa ocupó un lugar central, no solo en términos políticos, pues efectuó, como se ha visto, un rol socializador dando vida a partidos políticos y asociaciones civiles, sino también en términos intelectuales, pues a través de ella las ideas que configuraron el pensamiento político circularon ampliamente por toda la nación.

61 Ulpiano González, "Observaciones curiosas. Sobre lengua castellana”, El Aviso, Bogotá, 1 de octubre, 1848, 3-4; Ricardo Vanegas, "Los Jesuitas”, El Siglo, Bogotá, 19 de octubre, 1848, 3-4.

62 Ulpiano González, "Mi Libro", El Aviso, Bogotá, 15 de octubre, 1848, 3.

63 "La Regeneración”, La Democracia, Cartagena, 17 de junio, 1852, 2. 
Las distintas facetas que desarrollaron los publicistas neogranadinos de mediados de siglo tuvieron un efecto decisivo sobre todas las actividades intelectuales y políticas, de ahí que se hubieran constituido en personajes centrales de los acontecimientos del periodo. No obstante, la historiografía les ha prestado poca atención a estos hombres que configuraron con sus acciones el pensamiento político y la práctica política colombiana, forjando así el carácter de los colombianos y las actitudes que estos han tomado frente a las diferentes vicisitudes propias de la democracia.

Por aquella significación trascendental considero que este texto no es concluyente en ninguno de los temas abordados, más bien es una propuesta para incentivar el estudio de la historia intelectual y de los intelectuales colombianos decimonónicos, con el objetivo de comprender los sucesos políticos e intelectuales como acciones propias de una comunidad política.

\section{BibLIOGRAFÍA}

\section{Fuentes primarias}

\section{Publicaciones periódicas}

“iiRevolución!!!”, La Civilización, Bogotá, 13 de junio, 1851.

“Para quién escriben los periódicos del ministerio y qué escriben?”, La República, Cartagena, 11 de julio, 1850.

“¿Quién debe ser electo presidente de la Nueva Granada?”, El Siglo, Cartagena, 22 de junio, 1848.

"A la cuestión”, El Sur-Americano, Bogotá, 4 de octubre 1849.

"De la democracia en Suramérica y particularmente en la Nueva Granada”, El Neo-Granadino, Bogotá, 30 de julio, 1852.

“El 7 de marzo de 1849”, La Democracia, Cartagena, 7 de marzo, 1850. "El ciudadano", El Ciudadano, Popayán, 13 de mayo, 1848.

"El Día”, El Día, Bogotá, 21 de junio, 1848.

"El Día”, El Día, Bogotá, 22 de enero, 1848.

"El Dr. Manuel Murillo, secretario de hacienda", La Democracia, Cartagena, 1 de agosto, 1850.

"El periodismo en América", El Sur-Americano, Bogotá, 2 de diciembre, 1849. 
“El periodismo en América”, La América, Bogotá, 16 de abril, 1848.

"El periodismo y los toros - la reconquista y los jesuitas", El Pasatiempo, Bogotá, 7 de febrero, 1852.

"El trece de junio", La América, Bogotá, 18 de junio, 1848.

"Estímulos", El Aviso, Bogotá, 24 de septiembre, 1848.

"Historia de la Nueva Granada desde su descubrimiento hasta el 20 de julio de 1810”, La Gaceta Mercantil, Santa Marta, 16 de agosto, 1848.

"Historia de la Nueva Granada”, El Nacional, Bogotá, 21 de octubre, 1848.

"Hombres de partido (segundo artículo)", La Democracia, Cartagena, 27 de junio, 1850.

“La discusión”, La Discusión, Bogotá, 19 de febrero, 1853.

"La prensa desencadenada", La Juventud Granadina, Bogotá, 15 de septiembre, 1849.

"La Reforma”, La Reforma, Bogotá, 20 de julio, 1851.

“La Regeneración”, La Democracia, Cartagena, 17 de junio, 1852.

“La República y la Monarquía”, El Día, Bogotá, 1 de enero, 1848.

"La vida de un editor en la Nueva Granada", El Charivari Bogotano, Bogotá, 5 de noviembre, 1848.

"Libertad de imprenta", La Civilización, Bogotá, 20 de marzo, 1851. "Los candidatos para la presidencia y su conducta actual", La Gaceta Mercantil, Santa Marta, 24 de mayo, 1848.

“Los Rojos y el Doctor Jorge Gutiérrez de Lara”, El Antioqueño Constitucional, Medellín, 29 de diciembre, 1850.

"Nuevos medios de Gobierno inventados por los hombres del 7 de marzo", La Civilización, Bogotá, 25 de abril, 1850.

“Opinión pública”, La Civilización, Bogotá, 8 de agosto, 1850.

"Prospecto", El Siglo, Bogotá, 8 de junio, 1848.

"Publicaciones nuevas", El Aviso, Bogotá, 28 de diciembre, 1848.

"Servicio público", La Reforma, Bogotá, 27 de julio, 1851.

"Situación de la república", La América, Bogotá, 23 de abril, 1848.

"Una publicación histórica”, El Día, Bogotá, 13 de septiembre, 1848.

Blanco, Juancho. "Guerra a quien la merezca”, El Neo-Granadino, Bogotá, 2 de septiembre, 1848.

Blanco, Juancho. "No soy ni seré periodista”, El Siglo, Bogotá, 21 de septiembre, 1848. 
Caro, José Eusebio y Mariano Ospina Rodríguez. "Fragmentos de una representación dirigida al ciudadano presidente de la república", La República, Cartagena, 6 de junio, 1850.

Caro, José Eusebio. "La Polémica de los rojos", La Civilización, Bogotá, 4 de octubre, 1849.

Caro, José Eusebio. "Remoción del Sr. José Eusebio Caro, uno de los Redactores de la Civilización, del destino de Contador general", La Civilización, Bogotá, 13 de septiembre, 1849.

El Redactor. “La Redacción”, El Cuatro de Julio, Pamplona, 17 de julio, 1850.

González, Florentino. "Caracteres Políticos”, El Neo-Granadino, Bogotá. 18 de febrero, 1853.

González, Florentino. "Un lugar común impugnado por segunda vez", El Neo-Granadino, Bogotá, 28 de enero, 1853.

González, Ulpiano. "Mi Libro”, El Aviso, Bogotá, 15 de octubre, 1848. González, Ulpiano. "Observaciones curiosas. Sobre lengua castellana”, El Aviso, Bogotá, 1 de octubre, 1848.

Kastos, Emiro. "Alpha”, El Neo-Granadino, Bogotá, 17 de octubre, 1850.

Kastos, Emiro. "La imprenta, la inteligencia y la fuerza", El Neo-Granadino, Bogotá, 26 de septiembre, 1851.

Los Redactores del Clamor, “¿Hay patriotismo en los rojos...?”, El Clamor nacional, Popayán, 19 de abril, 1851.

Los Redactores. "Honor al espíritu público", Suplemento a "El cuatro de julio", Pamplona, 27 de febrero, 1850.

Madiedo, Manuel María. "¡Cuándo seremos verdaderos republicanos!”, El Pasatiempo, Bogotá, 5 de mayo, 1852.

Posada, Joaquín Pablo. "Cobardía”, El Neo-Granadino, Bogotá, 4 de mayo, 1850.

Un Patriota. "Sr. Editor de la Gaceta mercantil", La Gaceta Mercantil, Santa Marta, 6 de septiembre, 1848.

Vanegas, Ricardo. "Los Jesuitas”, El Siglo, Bogotá, 19 de octubre, 1848. Zamborondon. “A mi Juanchito”, El Aviso, Bogotá, 13 de agosto, 1848.

\section{Libros}

264 Acosta, Joaquín. Compendio histórico del descubrimiento y colonización de la Nueva Granada en el siglo décimo sexto. París: Imprenta de Beau, 1848. 
Mosquera, Tomás Cipriano. Memoria sobre la geografía física y política de la Nueva Granada. Nueva York: Imprenta de S. W. Benedict, 1852.

Plaza, José Antonio. Compendio de la historia de la Nueva Granada, desde antes de su descubrimiento, hasta el 17 de noviembre de 1831. Bogotá: Imprenta del Neo-Granadino, 1850.

Plaza, José Antonio. Memorias para la historia de la Nueva Granada desde su descubrimiento hasta el 20 de julio de 1810. Bogotá: Imprenta del Neo-Granadino, 1850.

Samper, José María. Apuntamientos para la historia política y social de la Nueva Granada. Bogotá: Imprenta del Neo-Granadino, 1852.

\section{Fuentes secundarias}

Acevedo, Rafael. "Hombres de letras en la provincia. Producción y comercio de libros en la República de Colombia, 1921-1874”. Anuario Colombiano de Historia social y de la Cultura Vol. 43 No. 1 (2016): 100-122.

Amaya Laverde, Isidoro. Apuntes sobre bibliografía colombiana. Bogotá: Imprenta de Vapor de Zalamea Herrán, 1882.

Arboleda, Gustavo. Diccionario biográfico y genealógico del antiguo departamento del Cauca. Bogotá: Biblioteca Horizontes, 1962.

Bushnel. David. "The Development of the Press in Great Colombia". The Hispanic American Historical Review Vol. 30 No. 4 (1950): 432-452.

Cardona, Patricia. "Historia, tradiciones editoriales y sociedad. las Memorias y el Compendio de José Antonio de Plaza. (Nueva Granada, 1850)". Historia Crítica, No. 57 (2015): 97-116.

Catálogo de publicaciones seriadas siglo XIX. Bogotá: Biblioteca Nacional de Colombia, t. 1, v. 1 y 2., 1995.

Escobar, Juan Camilo. "Impresos, periódicos en Antioquia durante la primera mitad del siglo XIX. Espacios de sociabilidad y de opinión de las élites letradas". Disfraz y pluma de todos. Opinión pública y cultura política, siglos XVIII y XIX. eds. Francisco Ortega y Alexander Chaparro. Bogotá: Universidad Nacional de Colombia, 2012. 499-526.

Jiménez, Andrés. "Intelectuales, política y religión en Colombia en el siglo XIX: José Manuel Groot y los escritores católicos”. Historia y Sociedad No. 31 (2016): 293-321. 
Loaiza, Gilberto. “El Neogranadino, 1848-1857: un periódico situado en el umbral". Disfraz y pluma de todos. Opinión pública y cultura política, siglos XVIII y XIX. eds. Francisco Ortega y Alexander Chaparro. Bogotá: Universidad Nacional de Colombia, 2012. 447472.

Loaiza, Gilberto. Manuel Ancízar y su época. Bogotá: Ediciones Plural, 2018.

Loaiza, Gilberto. Poder letrado. Ensayos sobre historia intelectual de Colombia, siglos XIX y XX. Cali: Programa editorial Universidad del Valle, 2014.

Mejía Cubillos, Javier. Diccionario biográfico y genealógico de la élite antioqueña y viejocaldense. Segunda mitad del siglo XIX y primera del XX. Pereira: Sello Editorial Red Alma Mater, 2012.

Mejía, Sergio. La revolución en letras. La historia de la revolución de Colombia de José Manuel Restrepo (1781-1863). Bogotá: Universidad de los Andes - Universidad EAFIT, 2007.

Ortega, Francisco y Alexander Chaparro. "El nacimiento de la opinión pública en la Nueva Granada, 1785-1830”. Disfraz y pluma de todos. Opinión pública y cultura política, siglos XVIII y XIX. eds. Francisco Ortega y Alexander Chaparro. Bogotá: Universidad Nacional de Colombia, 2012. 37-126.

Ospina, Joaquín. Diccionario biográfico y bibliográfico de Colombia, Tomo II y III. Bogotá: Editorial Águila, 1927.

Pacheco, Margarita. "Escribiendo para el pueblo: La prensa en Cali 1848-1854”. Historia y Espacio No. 15 (1994): 27-48.

Posada Carbó, Eduardo. “¿Libertad, libertinaje, tiranía? La prensa bajo el Olimpo Radical en Colombia, 1863-1885”. El radicalismo colombiano del siglo XIX. ed. Rubén Sierra. Bogotá: Universidad Nacional de Colombia, 2006. 147-166

Posada Carbó, Eduardo. "Newspapers, politics, and election in Colombia, 1830-1930”. The Historical Journal Vol. 53 No. 4 (2010): 939962.

Rosanvallon, Pierre. Por una historia conceptual de lo político. Buenos Aires: Fondo de Cultura Económica, 2003.

Rubio, Alfonso y Juan David Murillo. Historia de la edición en Colombia 1738-1851. Bogotá: Instituto Caro y Cuervo, 2017. 
Ruíz, Paola. "La libertad de imprenta en la Nueva Granada: los juicios contra El Alacrán a mediados del siglo XIX". Anuario Colombiano de Historia Social y de la Cultura Vol. 43 No. 2 (2016): 279-305.

Sabato, Hilda. "Nuevos espacios de formación y actuación intelectual: prensa, asociaciones, esfera pública (1850-1900)". Historia de los intelectuales en América Latina. ed. Jorge Myers. Buenos Aires: Katz Ediciones, 2008. 387-411.

Silva, Renán. República Liberal, intelectuales y cultura popular, Medellín: La Carreta Editores E. U., 2005.

Vanegas, Isidro. Todas son iguales: Estudios sobre la democracia en Colombia. Bogotá: Universidad Externado de Colombia, 2011.

Wood, Gordon. La Revolución Angloamericana como revolución. Bogotá: Ediciones Plural, 2019.

Para citar este artículo: Becerra Mora, José Camilo. "Escritores Públicos y Prensa en la Nueva Granada, 1848-1853”, Historia Caribe Vol. XVI No. 38 (Enero-Junio 2021): 237-267. DOI: https://doi. org/10.15648/hc.38.2021.2820 